Dicle University Journal of Engineering (DUJE)

Araştırma Makalesi / Research Article

\title{
Kaldırma ve İletme Makinalarında Kullanılan Halatlarının Deneysel ve Nümerik Analizi
}

\section{Experimental and Numerical Analysis of Steel wires used in Materials Handling Systems}

\section{Berna Bolat *, Birgül Aşçioğlu Temiztaş², Muharrem Erdem Boğoçlu ${ }^{3}$, Burak Bayraktaroğlu ${ }^{4}$}

${ }^{1}$ Yıldız Teknik Üniversitesi ,Makina Mühendisliği Bölümü, İstanbul, balpan@yildiz.edu.tr

${ }^{2}$ Yıldız Teknik Üniversitesi ,Makina Mühendisliği Bölümü, İstanbul, birgul@yildiz.edu

${ }^{3}$ Yıldız Teknik Üniversitesi ,Makina Mühendisliği Bölümü, İstanbul, bogoclu@yildiz.edu.tr

${ }^{4}$ TMMOB Makina Mühendisleri Odası Bursa Şubesi, Bursa, burak.bayraktaroglu@ mmo.org.tr

\begin{tabular}{|c|c|}
\hline MAKALE BİLGİLERİ & ÖZET \\
\hline Makale geçmişi: & \multirow{6}{*}{$\begin{array}{l}\text { Çelik halatlar, esneklikleri ve yüksek mukavemete sahip olmaları sebebiyle yük kaldırma makinalarında en çok } \\
\text { kullanılan elemanlardır. Bir öz etrafına sarılmış birçok ince telden oluşmuşlardır. İnce teller karmaşk geometrik } \\
\text { yolları izleyerek bir araya gelirler ve halatı oluştururlar. Bu nedenle tel halatlar, sanayide yüksek dayanıma sahip } \\
\text { yük kaldırma elemanlardır. Bu çalışmada küçük çaplı halatlar için hem deneysel çalışma hem de nümerik olarak } \\
\text { modelleme yapılmış ve modelin doğruluğu tespit edilmiştir. Büyük çaplı halatlarda deneysel olarak halatı } \\
\text { koparmak çok zor ve maliyetli olduğu için bilgisayar ortamında üç boyutlu modeli oluşturulmuş ve modele eksenel } \\
\text { kuvvetler uygulanarak, yük altında uzamaları tespit edilmiştir. Analiz programı yardımıla çelik halat } \\
\text { modellerinin analizleri gerçekleştirilerek deneysel değerlerle karşılaştırılmış ve sonuçların birbiriyle uyumlu } \\
\text { oldukları görülmüştür. }\end{array}$} \\
\hline Geliş: 19 Şubat 2020 & \\
\hline Düzeltme: 6 Haziran 2020 & \\
\hline Kabul: 3 Temmuz 2020 & \\
\hline Anahtar kelimeler: & \\
\hline $\begin{array}{l}\text { Krenler, Halatlar, Mal } \\
\text { Tașımacılığ } 1 \text {, Nümerik }\end{array}$ & \\
\hline
\end{tabular}

\begin{tabular}{|c|c|}
\hline ARTICLE INFO & ABSTRACT \\
\hline Article history: & \multirow{6}{*}{$\begin{array}{l}\text { Steel ropes are the most used elements in load lifting machines due to their flexibility and high strength. They } \\
\text { consist of many thin strings wrapped around a core. Thin strands come together following complex geometric } \\
\text { paths and form the rope. Therefore, wire ropes are load-lifting elements with high strength in the industry. In this } \\
\text { study, both experimental and numerical modeling was done for small diameter ropes and the accuracy of the model } \\
\text { was determined. Since it is very difficult and costly to apply the tensile load experimentally in large diameter steel } \\
\text { ropes, three-dimensional models were created in the computer environment and axial forces were applied to the } \\
\text { models and their elongation under load was determined. With the help of the analysis program, the analysis of the } \\
\text { steel rope models was carried out and it was concluded that the results were compatible with each other by } \\
\text { comparing with the experimental values. }\end{array}$} \\
\hline Received: 19 Feb. 2020 & \\
\hline Revised: 6 June 2020 & \\
\hline Accepted: 3 July 2020 & \\
\hline Keywords: & \\
\hline $\begin{array}{l}\text { Cranes, Ropes, Material } \\
\text { Transportation, Numerical }\end{array}$ & \\
\hline
\end{tabular}

* Sorumlu yazar / Correspondence

Berna BOLAT

$\bowtie$ balpan@yildiz.edu.tr 


\section{Giriș}

Tel halatlar, esneklikleri ve yüksek mukavemete sahip olmaları sebebiyle yük kaldırma makinalarında en çok kullanılan elemanlardır. Bir öz etrafına sarılmış şekil bağ ile bir arada duran birçok ince telden meydana gelen halatlarda, yükün eşit olarak paylaştırılması ve büyük eksenel yükleri düşük eğilme ve burulma rijitliği ile taşımaları beklenilmektedir. Esnek yapıları, makara veya tamburlar üzerinde bükülüp, sarılmalarına imkân verir. Sağladıkları bu avantajlar nedeniyle kren sistemlerinde kullanılmaktadırlar.

Çelik halatla ilgili literatürde hem deneysel hem de nümerik çalışmalar mevcuttur. İmrak ve Erdönmez [1] tarafindan yapılan nümerik ağırlıklı bir çalışmada çelik halat modelleri oluşturularak halatı oluşturan tellerin denklemleri çıkartılmıştır. Rotaları çizilip ağ yapıları oluşturulan modelin analizi sonucunda, eksenel yönde uygulanan kuvvetin halatı etkilediği bunun ana nedeninin halat içindeki boşluklardan kaynaklandığı belirtilmiştir. İmrak ve Salman [2] bir diğer çalışmada, test numunelerinin çekme cihazı çenelerine bağlanabilmesi için farklı yöntemler denemiş ve yöntem sonuçlarını listelemişlerdir. Halat çekme deneyi sonucunda uygulanan yöntemler arasinda en iyi sonucun uçlara yapılan çinko döküm işlemi sonucu olduğu tespit edilmiştir.

Nümerik ve deneysel karşılaştırmalı bir başka çalışmada, Stanova ve arkadaşları [3] sırasıyla halata ait CAD tasarımı oluşturup sonlu elemanlar yöntemini kullanarak analiz işlemlerini gerçekleştirmişlerdir. Bu modelde halatı oluşturan teller tek tek tasarlanıp montaj işlemiyle birleştirilmiştir. Diğer bir çalışmada ise; 6x19 çelik halatlar üzerinde çalışılmış ve oluşturulan CAD modelleri ile yapılan analiz sonuçları çekme deneyi sonuçları ile karşılaştırılmıştır. Ayrıca farklı sarım tiplerine sahip aynı ölçülerdeki halatların analiz sonuçları ve farklı halat boyları için yapılan test işlemi sonucu ölçülen boyca uzamalar, bilgisayar analiz sonuçlarıyla karşılaştırılmıştır [4].

Bir diğer çalışmada, 7x7 ve 7x19 boyutundaki halatlar modellenerek, farklı temas koşulları için analizleri gerçekleştirilmiş ve karşılaştırması yapılmıştır. Tek bir sarımdan oluşan halatlarda temas koşullarının değişiminin boyca uzama üzerinde belirgin bir etki yaratmadığı, fakat çok sayıda sarımdan oluşan halatlarda temas koșullarındaki değișimin boyca uzamayı değiștirdiği bu çalışma kapsamında yapılan analiz sonuçlarından görülmektedir [5].

Malzeme farkını irdeleyen bir diğer çalışma Wenzheng tarafindan 6x36 boyutunda, çelik özlü olmayan bir halat için yapılmıştır. Halatın CAD tasarımı oluşturulmuş ve analiz programıyla gerilme dağılımı ve deformasyon değerleri incelenmiștir. Bu çalışmada halatın özünü oluşturan kısım için ayrı malzeme tanımları kullanılmıştır [6].

Diğer bir çalışmada halatın boyut ve malzeme özellikleri yanında farklı sarım açıları da irdelenmiş; analitik çözümler ile bilgisayar analiz sonuçları karşılaştırılmıştır. Çalışmada sarım açısının halat üzerindeki etkisi gösterilmiştir. [7].

Yaptığımız bu çalışmada, $3 \mathrm{~mm}, 8 \mathrm{~mm}$ ve 18 $\mathrm{mm}$ çapa sahip halatların bilgisayar ortamında çekme testlerinin yapılabilmesi için, üretim sonrası ölçüleri dikkate alınarak Solidworks ${ }^{\circledR}$ CAD programı ile model oluşturulmuş, Ansys ${ }^{\circledR}$ yazılımı kullanarak analizleri yapılmıştır. Ayrıca 3 ve $8 \mathrm{~mm}$ halatların çekme deneyi yapılarak kopma yükleri tespit edilmiştir. Bu çalışmada deneysel çalışmalar ile nümerik çalışmaların karşılaştırılması $3 \mathrm{~mm}$ ve $8 \mathrm{mmm}$ çaplar için yapılmış ve modelin doğruluğu tespit edilmiştir. $18 \mathrm{~mm}$ halatlar için deneysel çalışmada halat koparılması için çalışılmış ancak halatın genellikle çene kısmına bağlantı yerlerinde deformasyona bağlı kopma görüldüğü için sonuçlar alınamamıştır. Bu problemi çözmek için halat uç kısımlarına çinko döküm yapılmış ancak 
yine kaymalar gözlemlenmiştir. $\mathrm{Bu}$ nedenle $18 \mathrm{~mm}$ çaplı halat için yapılan bu deney sonuçları bu çalışmada verilmemiş, sadece deneysel verilerden ve Costello [8] teoreminden oluşturulan grafik eğimi referans alınarak değerlendirme yapılmıştır. $\mathrm{Bu}$ çalışmada amaç kopma yükü tespit edilemeyen kalın çaplı halatlara ait kopma dayanımı değerlerinin nümerik yöntemlerle tespit edilebilmesini sağlamaktır.

\section{Materyal ve Yöntem}

- Çalışmada $3 \mathrm{~mm}, 8 \mathrm{~mm}$ ve $18 \mathrm{~mm}$ çapa sahip çelik halatların eksenel yük altındaki davranışları ele alınmıştır.

- Test ve analiz yöntemi iki aşamada gerçekleştirilmiştir. Bunlar;

- Halatların modellenmesi

- Halatın Sonlu Elemanlar Yöntemi İle Analizi'dir.

- Sonlu eleman modeli kopma yükü ve deformasyon değerleri için tüm çaplar için uygulanırken; deneysel çalışmada tüm farklı çaplar için eksenel yük altındaki davranış elde edilememiştir. Deneysel çalışmada $3 \mathrm{~mm}$ ve $8 \mathrm{~mm}$ çapa sahip halat numuneleri kopma cihazına bağlanmış ve farklı yükler etkisi altında kopma dayanımı ve deformasyon değerleri ölçülmüştür. $\mathrm{Bu}$ çelik halatların hem kopma yükü hem de deformasyon değerleri elde edilmiştir. Aynı çalışma $18 \mathrm{~mm}$ çapa sahip çelik halat için tekrarlanamamıştır.

- Deney $3 \mathrm{~mm}$ ve $8 \mathrm{~mm}$ için yapılırken, aynı deneyin $18 \mathrm{~mm}$ çapa sahip halat numunesi için yapılamaması nedeni; halatın bağlantı noktalarında oluşan gerilme yığılmaları nedeniyle halatın bağlantı noktalarından kopmasıdır. Bunu önlemek amacıyla farklı tasarımlar denenmiş ancak testler esnasında bağlantı noktalarındaki kayma ve ideal bağlantı tipinin saptanamaması deneyin yapılmasını daha da zorlaştırmıştır. $\mathrm{Bu}$ sorunları aşabilmek için özel ekipman ve tasarımlara ihtiyaç duyulmuş bu da maliyeti arttırmıştır. $\mathrm{Bu}$ nedenle bu çalışmada deneysel olarak $18 \mathrm{~mm}$ çapa sahip halatların kopma yükü ve deformasyon değerleri elde edilememiştir.

- $3 \mathrm{~mm}$ ve $8 \mathrm{~mm}$ çaplara sahip çelik halatlar için sonlu elemanlar modeli ile deneysel verilerin karşılaştırılması yapılmıştır. Sonlu elemanlar modeli sarımların hem sürtünmeli hem de sürtünmesiz bağla temas ettirilmesiyle oluşturulmuştur. Bunun nedeni temas bölgesindeki belirsizliklerdir. Yüklemeye bağlı sarımlar birbiriyle temas edebilir ya da etmeyebilir. $\mathrm{Bu}$ nedenle iki durumu da ortaya koyan bir model oluşturulmuştur.

- Sonuç olarak farklı tiplerdeki halatların telleri arasındaki çeşitli temas ve sürtünme kabulleri için yük-uzama grafikleri oluşturulmuştur.

\section{Halatın Modellenmesi}

Çelik halatlar genellikle bir öz etrafina belli bir düzende sarılmış çelik tellerden oluşur. $\mathrm{Bu}$ çalışmada, modelin oluşturulması için 6x19 IWRC model halat ele alınmıştır. Referans halat bağımsız çelik özlü, her biri 19 adet telden oluşan 6 kordondan, düzenli sarıma sahip, sağ sarımlı bir halattır. Her biri 6 adet telden meydana gelen 6 sarımla birlikte, 6 adet telden meydana gelen en iç sarım halatın çelik özünü oluşturmaktadır. Modellemede Solidworks ${ }^{\circledR} \quad$ yazılımı kullanılmıştır. Çalışmada $3 \mathrm{~mm}, 8 \mathrm{~mm}$ ve $18 \mathrm{~mm}$ için üç farklı model oluşturulmuştur. Kullanılan tüm ölçüler üretilmiş halat üzerinden alınarak çizim programına girilmiştir. Halat malzemesi olarak kullanılan çelik Halat/İzmit üretimi olup; seri numaras1 1270-16'dir. Halata ait sonlu elemanlar modelinde kullanılan malzeme özellikleri Tablo 1'de verilmiştir.

Tablo1. Malzeme özellikleri

\begin{tabular}{lll}
\hline Simge & Özellik & $\begin{array}{l}\text { Alınan } \\
\text { Değer }\end{array}$ \\
\hline $\boldsymbol{E}$ & Elastisite Modülü & $\begin{array}{l}190000 \\
\mathrm{~N} / \mathrm{mm}^{2}\end{array}$ \\
\hline $\boldsymbol{\rho}$ & Yoğunluk & $7850 \mathrm{~kg} / \mathrm{m}^{3}$ \\
\hline $\boldsymbol{\nu}$ & Poisson oranı & 0,3 \\
\hline $\boldsymbol{\mu}$ & Sürtünme Katsayısı & 0,1 \\
\hline
\end{tabular}


Tasarlanan halatın kesit görünüşü ise Şekil 1.'de verilmiştir.
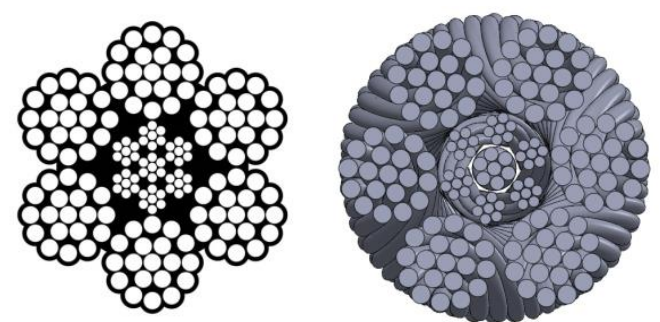

Şekil 1. Tasarlanan halatın kesit görünüşü

Modellerin oluşturulması amacıyla her bir sarım, sarımın ortasından geçen rotaya göre süpürülürken, aynı zamanda kendi etrafinda döndürülmüşsür. Merkez sarımı oluşturan dış teller $20 \mathrm{~mm}$ mesafede tam bir tur atacak şekilde bükülmüşken, en dış sarımı oluşturan dış teller $31,25 \mathrm{~mm}$ mesafede bir tam tur atmaktadır. Ayrıca, dış sarım iç sarımlar etrafındaki bir tam dönüşünü $120 \mathrm{~mm}$ mesafede tamamlamaktadır. Dış sarım, iç sarımlar etrafında $120 \mathrm{~mm}$ halat en iç sarımdan başlayarak diş sarımlara doğru modellenmiş ve sarımlar eksenel çoğaltma komutuyla çoğaltılarak halat oluşturulmuştur (Şekil 2.)

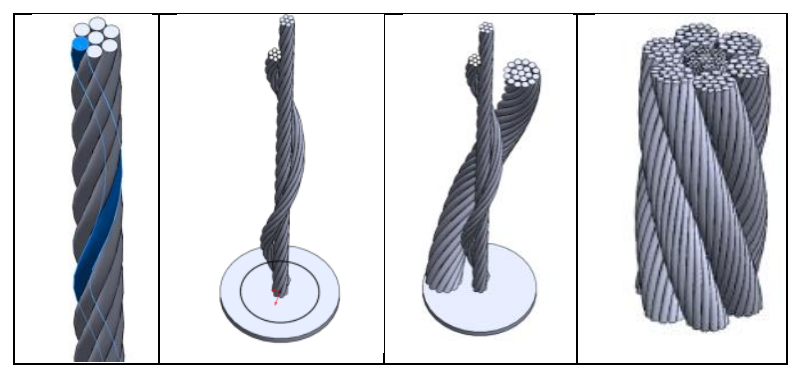

Şekil 2. Halatın modelinin oluşturulması

Halatı oluşturan sarımlar eklendikçe, model karmaşık bir yapıya bürünmektedir. Model 1 olarak isimlendirilen tasarım 7 katı gövdeden oluşurken, Model 2 halat 49 katı gövdeden, Model 3 halat ise 163 kat1 gövdeden oluşmaktadır. (Şekil 3.)

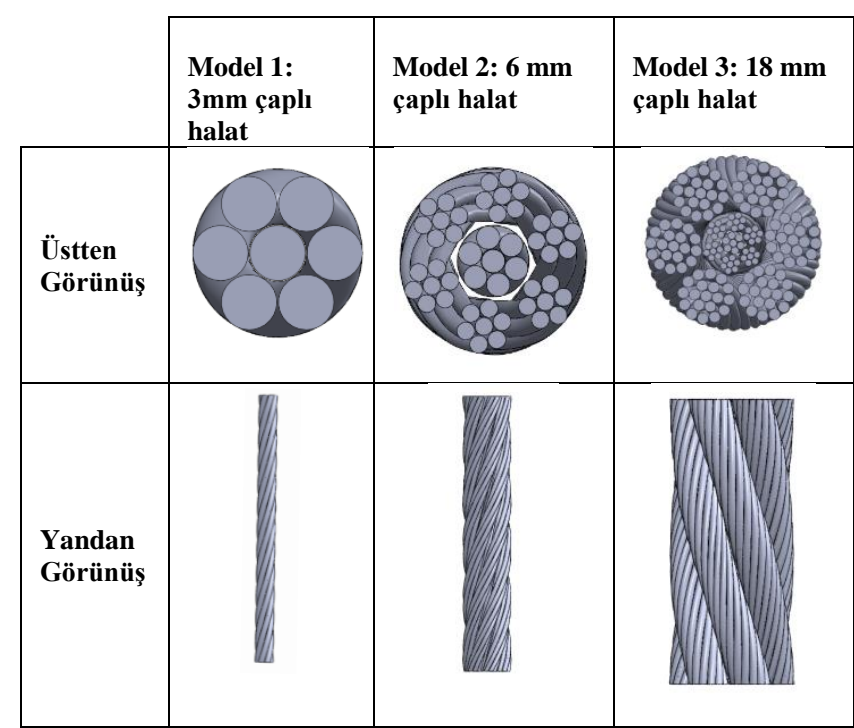

Şekil 3. Model (1-3) halatlar

\section{Halatın Sonlu Elemanlar Yöntemi İle Analizi}

Halatın bilgisayar ortamındaki testleri ANSYS $^{\circledR}$ Workbench yazılımı kullanılarak bilgisayar ortamında yapılmış ve modelde eksenel çekme kuvveti analizleri gerçekleştirilmiştir. ANSYS Workbench yazılımında Structural Analysis modülü kullanılarak lineer analiz yapılmıştır. Yapılan işlemler sırasıyla modeli oluşturma, ağ yapılarına bölme, sınır şartlarını atama ve zorlanma tiplerini belirleme işleminden sonra sonuç olma işlemidir. SOLIDWORK's de geometri oluşturulduktan sonra, model ANSYS ortamına taşınmış ve sonrasında mesh (ă̆ oluşturma) gerçekleştirilmiştir. Meshleme işlemlerinde "mesh sweeping metod" kullanılmıştır. Bu teknik kullanılarak, gövdeler hexahedral elemanlarla ayrılmıştır. Swept body metoduyla oluşturulan mesh yapılarında, eleman ve dügüüm noktası sayısı daha az olmaktadır. Bu nedenle parçanın sonlu elemanlara ayrilması daha az zaman almıştır.

Yapılan çalışmada temas durumları, yüzeyler tamamen birbirine bağlı "Bonded" veya sürtünmeli temas durumu "Frictional" olarak seçilmiştir. Bunun nedeni temas bölgesinin tam olarak kestirilememesi nedeniyledir. 
Temas bölgesi temas edebilir ya da etmeyebilir. Bunun yanında model karmaşıklaştıkça temas yüzey sayısı arttmakta ve çözüm zorlaşmaktadır. Model 1'deki halat için 13 temas yüzeyi tanımlanırken, Model 3'teki halat için 383 temas yüzeyi tanımlanmıştır.

Çekme testi işlemi incelendiğinde, halatın cihaza sabitlenmiş olan uçları dönme hareketi yapamayacağından, halat sadece çekme yönünde uzayacaktır. Sonlu elemanlar yönteminde eleman boyutu sonucu etkileyen en önemli parametrelerdendir. Olması gerektiğinden daha az elemanla analiz işlemi gerçekleştirildiğinde, değerler yakınsamadığından sonuç bulunamamakta veya hatalı sonuçlara ulaşılmaktadır. Eleman boyutu çok küçük seçildiğinde ise, daha çok eleman ve düğüm noktası nedeni ile çözüm süresi oldukça uzamaktadır. Çözüm zamanını azaltmak için sınır koşullar sabit tutularak mesh boyutu optimize edilmiş ve analiz işlemleri gerçekleştirilmiştir.

Sonlu elemanlara ayırma işlemlerinde "mesh sweeping method" kullanılmıştır. Bu metoda göre gövdeler etkin bir şekilde hexahedral elemanlarla ayrılmaktadır. Swept body metoduyla oluşturulan mesh yapılarında, eleman ve dügüum noktası sayısı az sayıda tutulabilmektedir [9]. Bu nedenle parçanın sonlu elemanlara ayrılması daha az zaman almaktadır (Şekil 4).

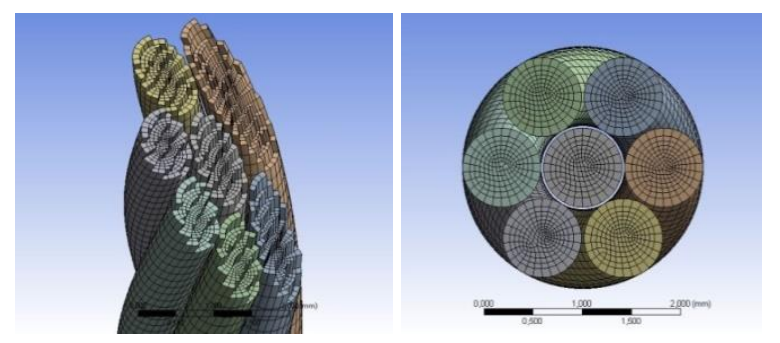

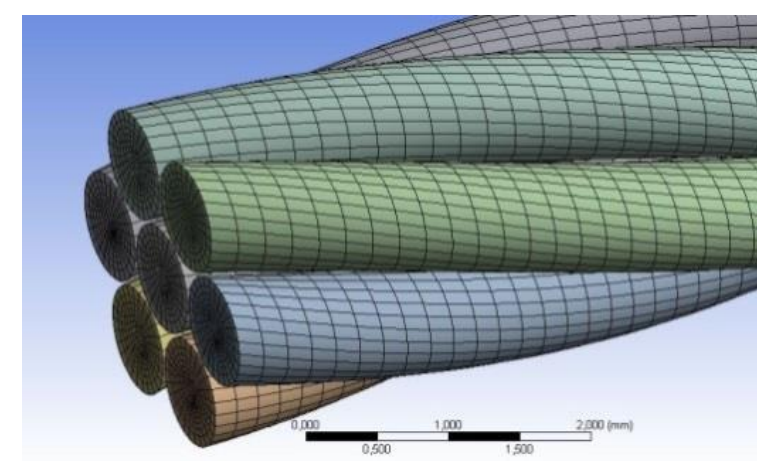

Şekil 4. Halatın mesh yapısı

Kullanılan sonlu elemanlar yirmi düğüm noktasına sahiptir ve her düğüm noktasının $\mathrm{x}$, $\mathrm{y}$ ve $\mathrm{z}$ ekseninde üç serbestlik derecesi vardır (Tablo.2).

Tablo 2. Eleman ve node sayılart

\begin{tabular}{ccc}
\hline Model No & Eleman Sayısı & Node sayısı \\
\hline 1 & 256822 & 1090723 \\
\hline 2 & 328565 & 1444754 \\
\hline 3 & 531340 & 2520256 \\
\hline
\end{tabular}

\section{Sonuçlar ve Tartışma}

- $\mathrm{Bu}$ çalışmada hedeflenen amaç; büyük çaplı halatlarda deneysel olarak kopma yükü ve deformasyon değerlerinin elde edilmesinin mümkün olmadığı durumlarda nümerik yönteme başvurulmasının tartışılmasıdır.

- $\mathrm{Bu}$ nedenle $3 \mathrm{~mm}, 8 \mathrm{~mm}$ ve $18 \mathrm{~mm}$ çapa sahip halatların eksenel yük etkisi altındaki davranışları; hem deneysel (18 mm'lik halat hariç) hem de nümerik olarak incelenmiş ve kopma yükü ve deformasyon değerleri elde edilmiştir.

- Deneysel çalışmada $3 \mathrm{~mm}$ çaplı halat ve 8mm çaplı halat için farklı çekme yükü etkisi altında deformasyon değerleri ölçülüp kopma dayanımı değeri elde edilmiştir. Aynı deney $18 \mathrm{~mm}$ çaplı çelik halat için de tekrarlanmış ancak halatın bağlantı noktalarındaki gerilme yı̆̆ılmalarından ötürü deney gerçekleştirilememiş ve kopma yükü ve deformasyon değerlerine ulaşılamamıştır. 
- Deneyde uygulanan çekme yükü değerleri her halat için, hem Costello [8] teorisi hem de çeliğe ait kopma yükü ve kesit alanı baz alınarak etki ettirilmiştir. Costello çalışmasında hem deneysel hem de teorik olarak farklı halat çapları için kopma yükü değerlerini karşılaştırmalı vermiştir. Costello'nun çalışmasında ayrıca görünen teorik ve deneysel olarak hesaplanan kopma yükü değerleri arasındaki farkın halat çapının belli bir değerinden sonra oldukça artmasıdır. Aşağıda verilen grafik bu durumu göstermektedir. Yani Costello'ya ait çalışmada da deneysel ve teorik veriler halat çapının belli bir değerinden sonra oldukça farklılık göstermektedir. $\mathrm{Bu}$ durum nümerik yöntemin özellikle büyük çaplar için kullanılmasının tartışılması gerektiğini ayrıca göstermektedir.

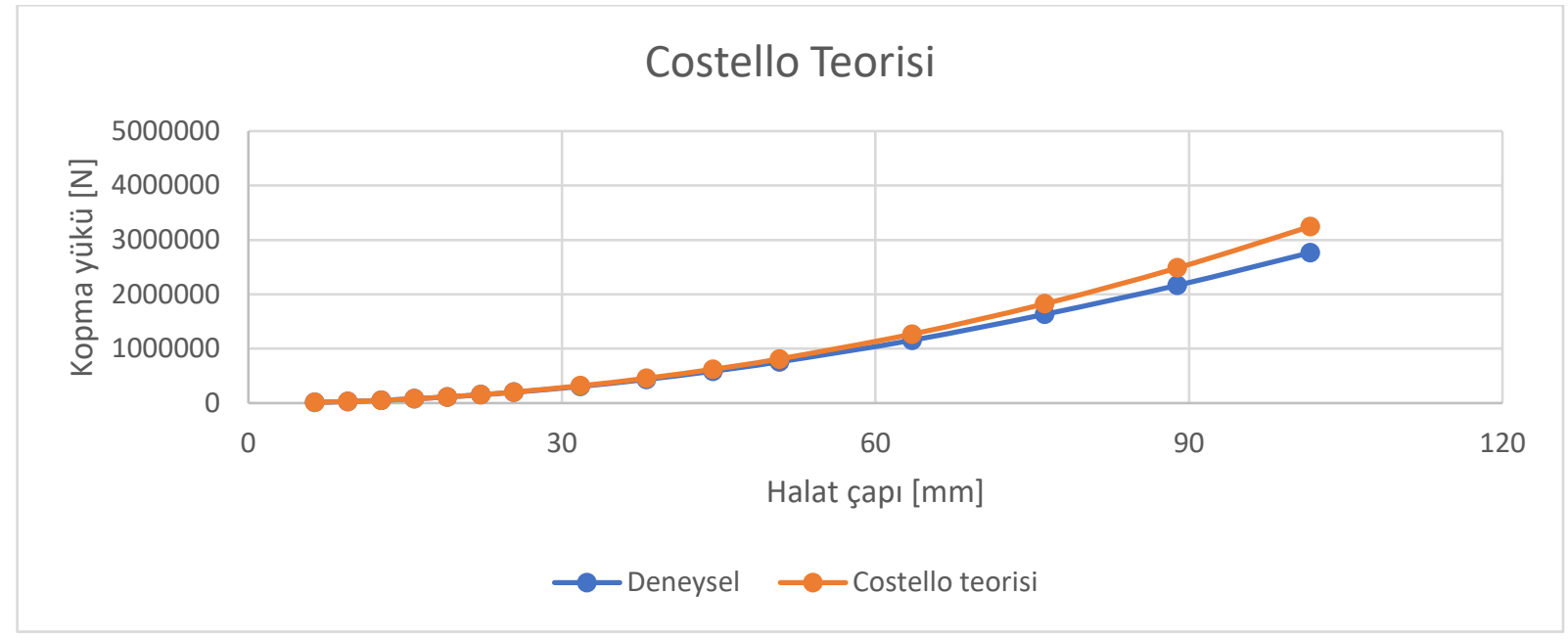

Şekil 5. Costello’ya göre çapma yüküne bă̆lı kopma yükü değerleri [8]

- $3 \mathrm{~mm}$ ve $8 \mathrm{~mm}$ çelik halatlar için elde edilen kopma yükü değerleri aşağıda tablo halinde verilmiştir. Deformasyon değerleri hesaplanırken bulunan bu kopma yükü değerleri referans alınmıștır (Tablo 3).

Tablo 3. Farklı halat çapına băglı kopma yükü değerleri

\begin{tabular}{cl}
\hline $\begin{array}{c}\text { Halat çapı } \\
{[\mathrm{mm}]}\end{array}$ & Kopma yükü [N] \\
\hline 3 & 4094 \\
\hline 8 & 20470 \\
\hline
\end{tabular}

- $3 \mathrm{~mm}$ çaplı çelik halat için elde edilen deneysel uzama değerleri ise şu şekildedir. Deney 1000 N'dan başlanılarak 3000N'a kadar 3 kez tekrarlanmıştır (Tablo 4).
Tablo 4. Model 1 için elde edilen deneysel yüzde uzama oranlarl

\begin{tabular}{clc}
\hline Yük[N] & Deneysel Uzama[mm] & \%Uzama \\
\hline 1000 & 0.0033 & 0.00825 \\
\hline 2000 & 0.0058 & 0.01450 \\
\hline 3000 & 0.0092 & 0.02300 \\
\hline
\end{tabular}

- $8 \mathrm{~mm}$ çaplı çelik halat için elde edilen deneysel uzama değerleri ise şu şekildedir. Deney 3000N'dan başlanılarak 21000N'a kadar 7 kez tekrarlanmıştır (Tablo 5).

Tablo 5. Model 2 için elde edilen deneysel yüzde uzama oranları

\begin{tabular}{clc}
\hline Yük[N] & Deneysel Uzama[mm] & \%Uzama \\
\hline 3000 & 0.0020 & 0.00500 \\
\hline 6000 & 0.0033 & 0.00825 \\
\hline 9000 & 0.0046 & 0.01150 \\
\hline 12000 & 0.0059 & 0.01475 \\
\hline 15000 & 0.0070 & 0.01750 \\
\hline 18000 & 0.0083 & 0.02075 \\
\hline 21000 & 0.0097 & 0.02425 \\
\hline
\end{tabular}


- Sonlu Elemanlar paket programı ANSYS Workbench kullanılarak çelik halatlara ait deformasyon değerleri hem $3 \mathrm{~mm}$ çaplı çelik halat, hem $8 \mathrm{~mm}$ çaplı çelik halat ve son olarak da $18 \mathrm{~mm}$ çaplı çelik halat için farklı yük etkileri altında çalışılmıştır. Model oluşturulurken iki farklı temas durumu, uygulanmıştır. Bunlar tam bağlantılı (bonded) ve sürtünmeli (frictional) yüzey teması tipleridir.

- Şekil 6'da Model 1 olarak tanımlanan 3mm çaplı çelik halatın çekme yükü altındaki yüzde uzama miktarları hem deneysel hem de sonlu elemanlar yöntemi ile yapılan analizlerde kullanılan iki farklı temas tipi için verilmiştir. Model 1 için kuvvet etkiyen yüzey sayısı 7'dir. Bilgisayar modelinden alınan minimum yüzey kesit alanı 3,52 mm2'dir. Diğer gerilmelerin dikkate alınmadığ 1 durumda (temas gerilmeleri v.b.) uygulanan kuvvete göre oluşacak gerilmeler kuvvetin modelden ölçülen yüzey alanına bölünmesiyle hesaplanmıştır. Deneylerde halatın kopma yükünün, $4094 \mathrm{~N}$ olduğu görülmüştür. Yapılan sonlu elemanlar analizleri sonucunda ise tam bağlantılı (bonded) ve

sürtünmeli (frictional) yüzey temas koşullarında halat tellerindeki boyca uzamalar arasında kayda değer bir fark olmadığ 1 tespit edilmiştir. İki model tipi de deneysel sonuçlara oldukça yakındır.

\section{Model1: 3 mm çaplı çelik halat için yüzde uzama değerleri}

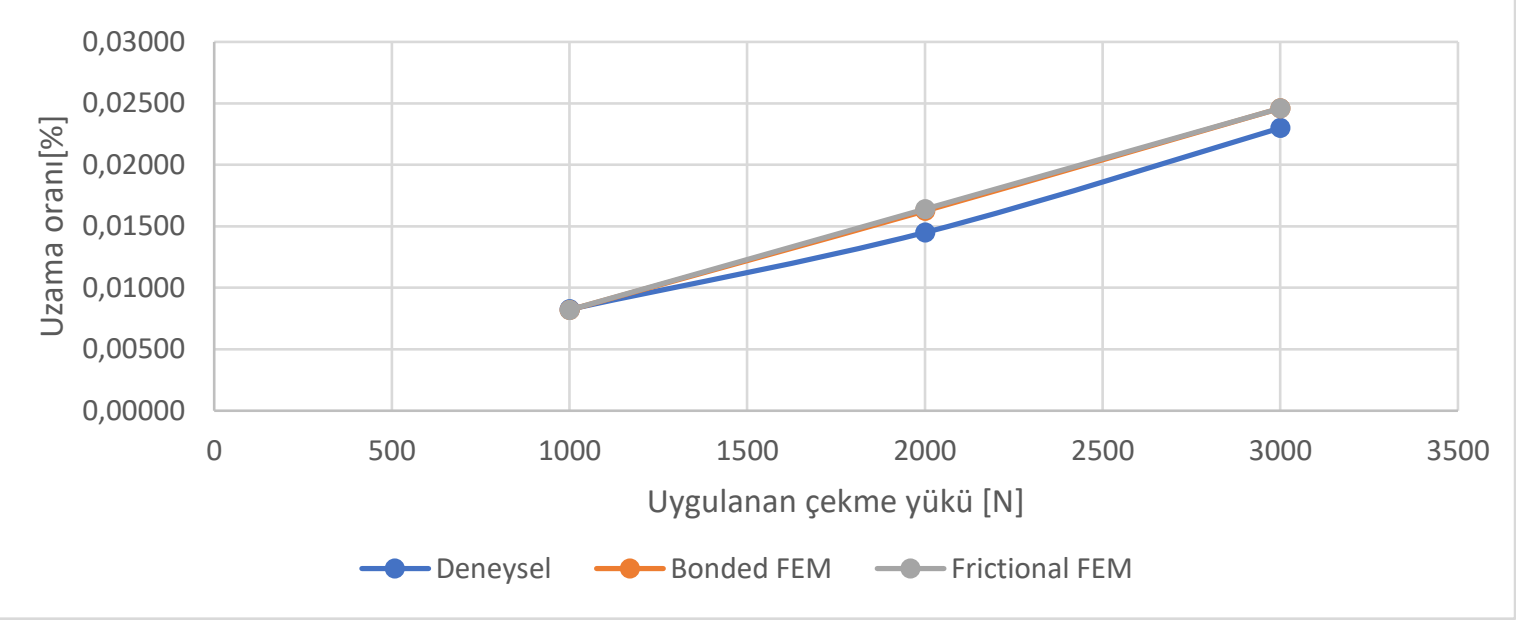

Şekil 6. Model 1 için farklı çekme bağlı yüküne deneysel ve nümerik uzama oranları

Şekil 7'de gösterilen grafikte görüldüğü gibi $8 \mathrm{~mm}$ çaplı halat için uygulanan çekme yükü altındaki uzama oranları yüzde olarak hem deneysel hem de sonlu elemanlar yönteminde kullanılan iki farklı temas tipi için verilmiştir. Model 2 için kuvvet etkiyen yüzey sayısı 49'dur. Model 2 halat için, bilgisayar modelinden alınan minimum yüzey kesit alanı
19,49 $\mathrm{mm}^{2}$ 'dir. Diğer gerilmeler göz önüne alınmadığı durumda (temas gerilmeleri v.b.) uygulanan kuvvete göre oluşacak gerilmeler kuvvetin modelden ölçülen yüzey alanına bölünmesiyle hesaplanmıştır. Halatın kopma değeri deneysel olarak yapılan çalışmada $20470 \mathrm{~N}$ olduğu görülmüştür. Nümerik analiz sonucunda sürtünmeli yüzey temasında boyca uzama değerinin daha fazla olduğu tespit 
edilmiş ve bonded tipi modelin deneysel sonuçlara daha yakın olduğu görülmüsştür.

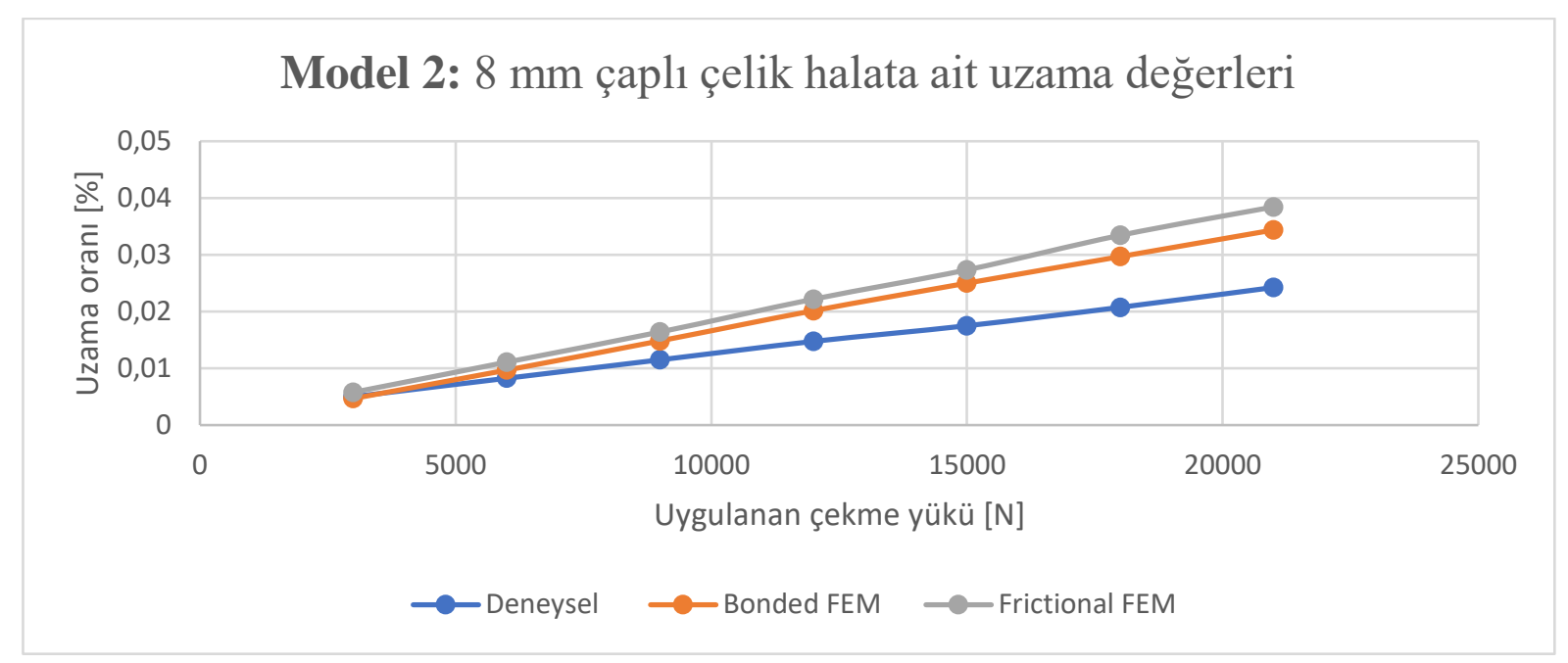

Şekil 7. Model 2 için farklı çekme bağlı yüküne deneysel ve nümerik uzama oranları

- Şekil 8'de gösterilen grafikte görüldüğü gibi $18 \mathrm{~mm}$ çaplı halat için uygulanan çekme yükü altındaki uzama oranları yüzde olarak yalnızca sonlu elemanlar yönteminde kullanılan iki farklı temas tipi için verilmiştir. Model 3 için kuvvet etkiyen yüzey sayısı 163 'dür. Bonded ve frictional temas tipi arasındaki fark halat çapı arttıkça etkiyen yüzey sayısının artmasına bağlı olarak artmaktadır.
- $\quad$ Model 3 halat için, bilgisayar modelinden alınan minimum yüzey kesit alanı 127,3 $\mathrm{mm}^{2}$ dir. Diğer gerilmeler göz önüne alınmadığ 1 durumda (temas gerilmeleri v.b.) uygulanan kuvvete göre oluşacak gerilmeler kuvvetin modelden ölçülen yüzey alanına bölünmesiyle hesaplanmıştır. Sürtünmeli yüzey temasinda boyca uzama daha fazladır.

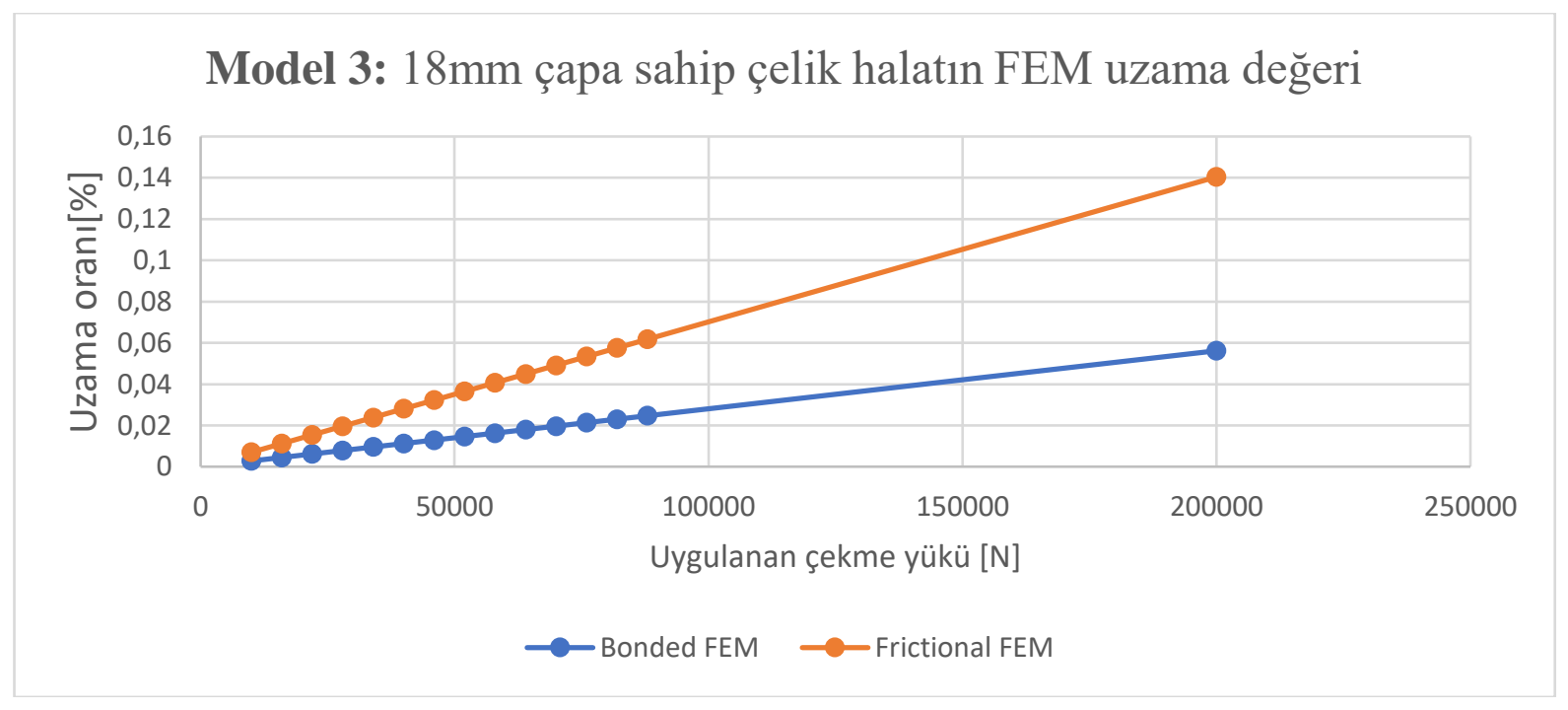

Şekil 8. Model 3 için farklı çekme yüküne bağlı nümerik uzama oranları 
- Deney $18 \mathrm{~mm}$ çaplı halat için tekrarlanamadığ 1 için nümerik analiz sonuçlarını karşılaştırma imkânımız bulunmamaktadır. Ancak 3mm çaplı çelik halat ve $8 \mathrm{~mm}$ çaplı çelik halat için elde edilen grafiklerdeki değişim değerleri referans alındığında, deneysel verilerin bonded tipi nümerik modele daha yakın sonuçlara sahip olabileceği görülmektedir.

- Test sonucunda elastik modülünün her kopma yükü değeri için az da olsa farklılık gösterdiği bunun da sarım etkisi nedeniyle olduğu gözlemlenmiştir. $\mathrm{Bu}$ durum analize dâhil edilmemiştir.

- Bonded ve frictional contact olarak modellenen yapıdaki değişiklikler gözlemlenmiş ve bonded yapının test sonucuna daha yakın olduğu test sonuçlarında ortaya koyulmuştur. $\mathrm{Bu}$ tip yapılarda bonded tipi contact yapılması hem analiz süresi hem de işlemlerin sadeleştirilmesi açısından önem taşımaktadır.

- Aşağıda üç farklı model için, farklı yük etkisi altında elde edilen eşdeğer gerilme değerleri verilmiştir. $\mathrm{Bu}$ değerler bonded temas tipi için elde edilmiştir.

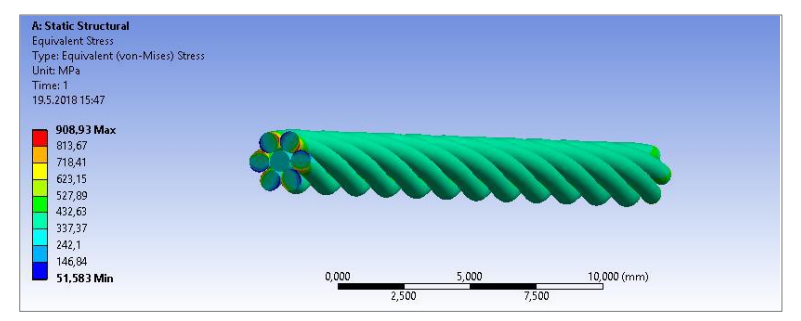

Şekil 9. Model 1 için 2000N altında oluşan eşdeğer gerilme durumu

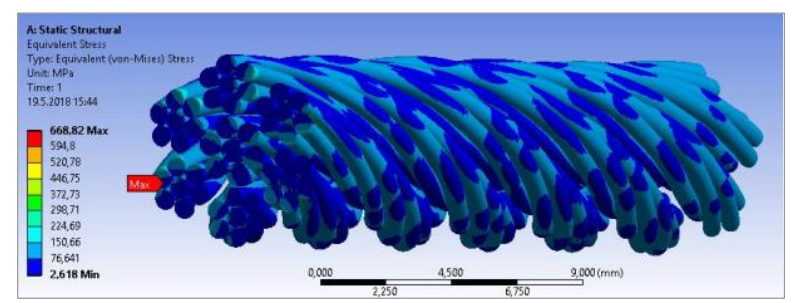

Şekil 10. Model 2 için 4000N altında oluşan eşdeğer gerilme durumu

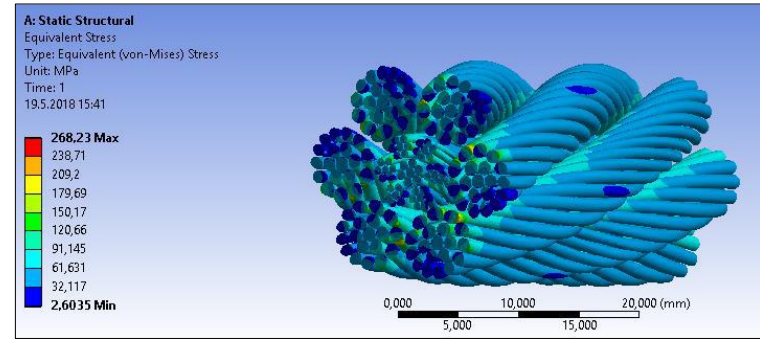

Şekil 11. Model 3 için 10000N altında oluşan eşdeğer gerilme durumu

- Yukarıdaki sonuçlarda bonded tipi kontağın gerilme analizlerinde tutarlı olduğu gösterilmiştir. Kopma gerilmesine testlerdeki uzama değerinde ulaşıldığ için bu tip kontak tanımı ile yapılan analizlerde elde edilen gerilme ve uzama değerlerle doğru sonucu ulaşılmıştır.

- Sonuç olarak deneysel olarak kopma yükü ve deformasyon değerleri tespit edilemeyen $18 \mathrm{~mm}$ çapa sahip halatın kopma yükü ve deformasyon değerlerinin düşük bir hata payıyla nümerik çalışmayla da tespit edilebileceği analiz sonuçlarından görülmüştür.

\section{Kaynaklar}

[1] İmrak, E., Erdönmez, C., (2010), On The Problem of Wire Rope Model Generation With Axial Loading,

Mathematical and Computational Applications, Vol. 15, No. 2,:259-268

[2] İmrak, E., Salman, Ö., (2010), Taşıyıcı Halatların Deneysel Gerilme Analizi, Asansör Sempozyumu, 21-23 Mayıs 2010, İzmir

[3] Stanova, E., (2011), Computer Modelling of Wire Strands and Ropes Part II: Finite Element-Based Applications, Advances Engineering Software, 42:322-331

[4] Jun, MA., (2008), Distribution of Wire Deformation Within Strands of Wire Ropes, J China Univ Mining \& Tecnology, Volume:18, No:3

[5] Kastratović, G., Vidanović, N., (2015), 3D Finite Element Modeling of Sling 80 Wire Rope In Lifting and Transport Processes, Transport, 2015 Volume 30(2): 129-134

[6] Wenzheng, Du, (2017), Finite Element Analysis of tehe Stress State of Rope Hoisting Equipment based on the ABAQUS, 2017 8th InternetionalConference on Mechanical and Intelligent Manifacturing Technologies, 03-06 Ocak 2017, Cape Town

[7] Ghoreishi, SR., (2007), Validity and Limitations of Linear Analytical Models for Steel Wire Strands Under Axial Loading, Using a 3D FE Model, International Journal of Mechanical Sciences; Volume 49:1251-1261

[8] Costello, G.D, (1997) Theory of wire rope, Mechanical Engineering Series, Springer

[9] Delta, General and High Performance Wire Rope,(2018),http://www.deltarigging.com/doc 